\title{
Portal of damage: a web-based finite element program for the analysis of framed structures subjected to overloads
}

\author{
María E. Marante ${ }^{\mathrm{a}, \mathrm{b}, *}$, Lorena Suárez $^{\mathrm{a}}$, Adriana Quero ${ }^{\mathrm{a}}$, Jorge Redondo ${ }^{\mathrm{a}}$, Betsy Vera ${ }^{\mathrm{a}}$, \\ Maylett Uzcategui ${ }^{a}$, Sebastián Delgado ${ }^{c}$, Leandro R. León ${ }^{a}$, Luis Núñez ${ }^{\mathrm{d}}$, Julio Flórez-López ${ }^{\mathrm{a}}$ \\ ${ }^{a}$ School of Engineering, University of Los Andes, Mérida 5101, Venezuela \\ ${ }^{\mathrm{b}}$ School of Civil Engineering, Lisandro Alvarado University, Barquisimeto, Venezuela \\ ${ }^{\mathrm{c}}$ School of Engineering, University of Zulia, Maracaibo, Venezuela \\ ${ }^{\mathrm{d}}$ School of Sciences, University of Los Andes, Mérida 5101, Venezuela
}

Received 8 April 2004; revised 10 April 2004; accepted 12 June 2004

\begin{abstract}
This paper describes a web-based finite element program called portal of damage. The purpose of the program is the numerical simulation of reinforced concrete framed structures, typically buildings, under earthquakes or others exceptional overloads. The program has so far only one finite element based on lumped damage mechanics. This is a theory that combines fracture mechanics, damage mechanics and the concept of plastic hinge. In the case of reinforced concrete frames, the main mechanism of deterioration is cracking of concrete. Cracking in a frame element is lumped at the plastic hinges. Cracking evolution in the plastic hinge is assumed to follow a generalized form of the Griffith criterion. The behavior of a plastic hinge with damage is described via the effective stress hypothesis, as used in continuum damage mechanics. The portal that can be accessed using any commercial browser (explorer, netscape, etc.) allows to:
\end{abstract}

(a) Create an account in a server.

(b) Make use of a semi-graphic pre-processor to create an input file with a digitalized version of the structure.

(c) Run a dynamic finite element program and monitor the state of the process.

(d) Download or upload input and output files in text format.

(e) Make use of a graphic post-processor.

(C) 2005 Published by Elsevier Ltd.

Keywords: Web-based program; Finite element analysis; Reinforced concrete; Lumped damage mechanics; Frames

\section{Introduction}

Massive collapse of civil engineering structures due to earthquakes occurs regularly around the world, more often in third-world countries. Post-disasters reconnaissance reports have shown that in many cases the failure is due

\footnotetext{
* Corresponding author. Address: Department of Structural Engineering, Facultad de Ingenieria, University of Los Andes, Merida 5101, Venezuela. Tel./fax: +582742402867 .

E-mail address: marante@ula.ve (M.E. Marante).
}

to deficiencies in the materials and or in the construction details. Probably, there are hundreds of thousands of structures in seismic areas everywhere that need retrofitting. Thus, the identification of these structures is an urgent task. But if ever done, this mission cannot be the job of a couple $\mathrm{R} \& \mathrm{D}$ engineers of some big company. On the contrary, it will probably be the work of an entire community of local engineers in the countries in question. It is also likely that this will be only a part-time activity for these engineers.

The identification of vulnerable structures can be carried out in two steps: first, the recognition of physical defects in 
the structure by using visual screening tools and second, the quantification of the potential impact of these defects. One of the tools that can be used for the latter goal is the numerical simulation of the behavior of structures under seismic overloads. Taking into account the size, the number and the complexity of this kind of structures (for instance buildings), the models used for this simulation must be not only realistic but also simple and effective. Those are obviously contradictory requirements. One of the possible compromises is represented by lumped damage mechanics.

Lumped damage mechanics is a general framework for the modeling and the numerical simulation of the process of deterioration and collapse of framed structures. This theory combines fracture mechanics, damage mechanics, and the concept of plastic hinge. Lumped damage mechanics has been used to model the behavior of reinforced concrete frames [1-4], and steel frames [5,6]. In the former case, the main mechanism of damage is cracking of the concrete. In lumped damage mechanics, cracking as well as plasticity are concentrated in plastic hinges. New sets of hinge-related variables are then introduced that can take values between zero and one as the conventional continuum damage variable. Expressions of the energy release rate of a plastic hinge are then derived and damage evolution in the plastic hinge is described by a generalized form of the Griffith criterion. Lumped models allow for a simple and effective representation of many civil engineering structures. However, any realistic model of the process of deterioration and collapse of structures is always expensive in computational terms.

Taking into account all the previous remarks, it seems that coupling nonlinear finite element programs with internet can be a very good tool for the diagnosis of potentially dangerous structures. This paper presents a prototype of this kind of program. It has been named 'portal of damage'. The system consists in a dynamic and nonlinear finite element program based on lumped damage mechanics that can be accessed via internet. The pre-processing, postprocessing and monitoring of the computations can be done using common commercial browsers such as Explorer or Netscape. With this kind of program, users do not need to buy expensive annual licenses and hardware but pay only for the time and resources consumed. If a systematic effort of security assessment is decided by some public or private organization, it will also minimize and centralize the funding needed for the computational requirements of the task.

This paper is organized as follows. In Section 2, the fundamental concepts of lumped damage mechanics are summarized. The portal is described in Section 3 and some numerical examples carried out with portal are presented in Section 4. The first and second examples are numerical simulations of tests reported in the literature. These results give an idea of the precision that can be expected with the portal. The final example presents the numerical simulation of the behavior of a frame designed after the current Venezuelan code subjected to earthquake forces.

\section{Lumped damage mechanics}

\subsection{Fundamental concepts of fracture mechanics}

In brittle materials, it is shown that the elastic stresses at the tip of an ideal crack tend to infinite independently of the level of external forces applied far from the crack. Thus, none of the classic failure criteria based on stresses or strains can be used to predict crack propagation. In a classic paper [7] (as described in [8]), Griffith proposed a criterion of crack propagation based on an energy balance. Griffith postulated that crack propagation can occur only if sufficient potential energy can be released to overcome the resistance to crack extension. In mathematical terms this criterion, denoted usually as the Griffith Criterion, can be written as:

$G=R$

where $G$ is called the energy release rate and is obtained after a structural analysis, and $R$ is denoted the crack resistance function and is assumed to be a material property. It can be shown that in a solid subjected to a tensile force $P$, the energy release rate is given by the following expression:

$G=-\frac{\partial U}{\partial A}=\frac{\partial U^{*}}{\partial A}=\frac{P^{2}}{2 B} \frac{\mathrm{d} F}{\mathrm{~d} a}$

where $U$ is the potential energy cumulated in the solid, $U^{*}$ is the complementary potential energy, $A$ is the crack area, $a$ the crack length, $B$ the specimen thickness and $F$ is the compliance defined as the load-point displacement per unit load (see Fig. 1). The crack resistance might be a function of the crack extension. The Griffith criterion establishes that crack propagation cannot occur if this energy release rate is lower than the crack resistance.

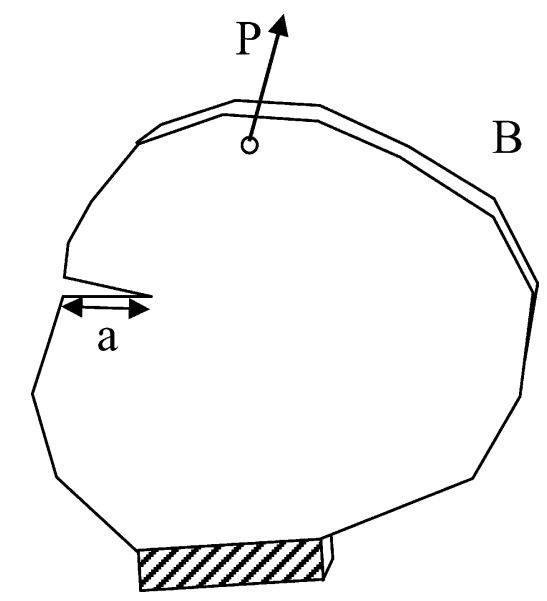

Fig. 1. Cracked plate of thickness $B$ subjected to a force $P$. 
(a)

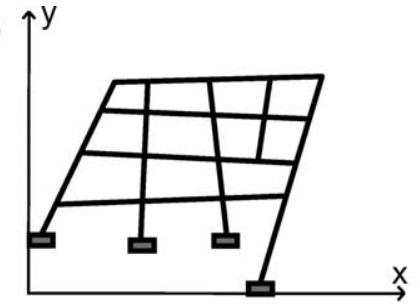

(c)

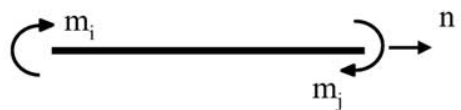

(b)

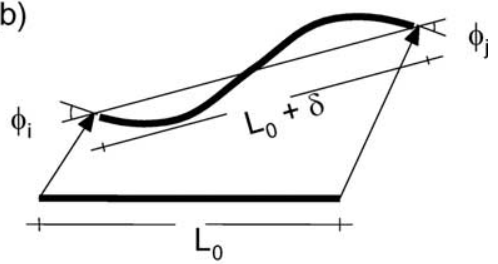

(d)

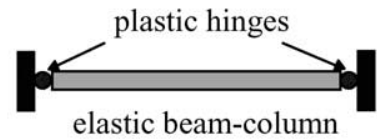

Fig. 2. (a) Planar frame (b) generalized strains of a frame member (c) generalized stresses of a frame member (d) lumped dissipation model.

\subsection{Flexibility matrix of a reinforced concrete frame member with cracking}

It can be seen that in order to describe crack propagation in a reinforced concrete element, within the framework of fracture mechanics, the potential energy or the flexibility of the cracked element must be obtained. Consider a planar frame as shown in Fig. 2a. A member between the nodes $i$ and $j$ is isolated from the frame. The generalized stress and strain matrices of the frame member are given, respectively, by $\boldsymbol{\sigma}^{\mathrm{t}}=\left(m_{i}, m_{j}, n\right)$ and $\boldsymbol{\varepsilon}^{\mathrm{t}}=\left(\phi_{i}, \phi_{j}, \delta\right)$, where the terms $m_{i}$ and $m_{j}$ represent the flexural moments at the ends of the element, $n$ is the axial force, $\phi_{i}$ and $\phi_{j}$ are the relative rotations of the frame member with respect to the chord and $\delta$ is the chord elongation (see Fig. $2 \mathrm{~b}$ and c).

Two major inelastic phenomena occur in a reinforced concrete structure subjected to overloads: yield of the reinforcement and concrete cracking. In order to model these phenomena in large and complex framed structures, the lumped dissipation model of a frame member is usually adopted. This model consists in assuming that all inelastic phenomena can be lumped at special locations called plastic or inelastic hinges. Therefore a frame member is considered as the assemblage of an elastic beam-column and two inelastic hinges as shown in Fig. 2d.

The conventional theory of elastic-plastic frames is obtained by the introduction of an internal variable that will be denoted in this paper generalized plastic strains $\varepsilon_{\mathrm{p}}^{\mathrm{t}}=\left(\phi_{i}^{\mathrm{p}}, \phi_{j}^{\mathrm{p}}, 0\right)$, where the symbols $\phi_{i}^{\mathrm{p}} y \phi_{j}^{\mathrm{p}}$ represent the plastic rotations of the inelastic hinges at the ends $i$ and $j$.

Lumped damage mechanics is obtained by the introduction of a new set of hinge-related internal variables. This variable, denoted damage, measures the crack density in the element as indicated in Fig. 3. Thus, the damage matrix is given by: $\mathbf{D}=\left(d_{i}, d_{j}\right)$, where $d_{i}$ and $d_{j}$ are damage parameters that can take values between zero (no cracking) and one (total damage). They represent cracking as lumped in the hinges $i$ and $j$.
In [2] the following elasticity law of a damaged reinforced concrete frame member was proposed:

$$
\begin{aligned}
& \boldsymbol{\varepsilon}-\boldsymbol{\varepsilon}_{\mathrm{p}}=\mathbf{F}(\mathbf{D}) \boldsymbol{\sigma} ; \\
& \mathbf{F}(\mathbf{D})=\left[\begin{array}{ccc}
\frac{F_{11}^{0}}{1-d_{i}} & F_{12}^{0} & 0 \\
F_{21}^{0} & \frac{F_{22}^{0}}{1-d_{j}} & 0 \\
0 & 0 & F_{33}^{0}
\end{array}\right]
\end{aligned}
$$

where $\mathbf{F}$ is the flexibility matrix of a cracked frame member and the terms $F_{i j}^{0}$ represent the coefficients of the elastic flexibility matrix as given in textbooks of structural analysis.

It can be noticed that for damage values equal to zero, $\mathbf{F}$ becomes the elastic flexibility matrix of the classic structural analysis theory. If a damage variable tends to one, the corresponding flexibility term tends to infinite (or the stiffness tends to zero) and the inelastic hinge behaves as the internal hinges of the classic frame analysis. It is assumed that the damage parameters evolve continuously from zero to one following the generalized Griffith criterion that will be defined in Section 2.3. In this way, stiffness degradation is represented by the model.

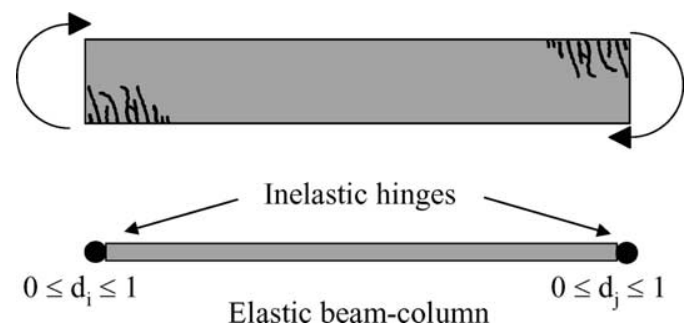

Fig. 3. Cracking representation in lumped damage mechanics. 


\subsection{Generalized Griffith criterion}

The complementary strain energy of a cracked frame member can be obtained from (3):

$U^{*}=\frac{1}{2} \sigma^{\mathrm{t}}\left(\varepsilon-\varepsilon^{\mathrm{p}}\right)=\frac{1}{2} \boldsymbol{\sigma}^{\mathrm{t}} \mathbf{F}(\mathbf{D}) \boldsymbol{\sigma}$

Then, the energy release rates of the plastic hinges are given by:

$$
\begin{aligned}
G_{i} & =\frac{\partial U^{*}}{\partial d_{i}}=\frac{1}{2} \boldsymbol{\sigma}^{\mathrm{t}} \frac{\partial \mathbf{F}(\mathbf{D})}{\partial d_{i}} \boldsymbol{\sigma}=\frac{m_{i}^{2} F_{11}^{0}}{2\left(1-d_{i}\right)^{2}} ; \quad G_{j} \\
& =\frac{m_{j}^{2} F_{22}^{0}}{2\left(1-d_{j}\right)^{2}}
\end{aligned}
$$

Therefore a generalized Griffith criterion for the inelastic hinge $i$ can be defined in the following terms: there will be damage evolution (i.e. crack propagation) in the plastic hinge $i$ only if the energy release rate $G_{i}$ reaches the value of the crack resistance of the hinge:

$\begin{cases}\dot{d}_{i}=0 & \text { if } G_{i}-R\left(d_{i}\right)<0 \text { or } \dot{G}_{i}-\dot{R}\left(d_{i}\right)<0 \\ \dot{d}_{i}>0 & \text { if } G_{i}-R\left(d_{i}\right)=0 \text { and } \dot{G}_{i}-\dot{R}\left(d_{i}\right)=0\end{cases}$

where $R$ is the crack resistance of the plastic hinge $i$. This function has been identified from experimental results [1]:

$R\left(d_{i}\right)=G_{\mathrm{cr}}+q \frac{\log \left(1-d_{i}\right)}{1-d_{i}}$

where $G_{\mathrm{cr}}$ and $q$ are member dependent parameters.

\subsection{Plastic behavior of a frame member with cracking}

Following [2], the behavior of a plastic hinge with cracking can be obtained by using the equivalent stress hypothesis. In continuum damage mechanics, this hypothesis states that the behavior of a damage material can be expressed by the same relations of the intact material if the stress is substituted by the effective stress. By analogy with continuum damage mechanics, the effective moment $\bar{m}_{i}$ on a plastic hinge is defined as:

$\bar{m}_{i}=\frac{m_{i}}{1-d_{i}}$

Thus, the yield function of a plastic hinge with damage and linear kinematic hardening is given by:

$f_{i}=\left|\frac{m_{i}}{1-d_{i}}-c \phi_{i}^{\mathrm{p}}\right|-k_{y} \leq 0$

where $c$ and $k_{y}$ are member-dependent properties. The elasticity law (3), the Griffith criterion (6) and the yield function (9) define the constitutive law of a frame member with cracking and yielding.

\subsection{Influence of the axial load}

The coefficients $k_{y}, c, G_{\mathrm{cr}}$ and $q$ for hinges $i$ and $j$ can be computed by the resolution of a system of nonlinear equations. Consider a monotonic loading on a reinforced concrete member. When the moment on the hinge reaches the cross-section cracking moment $M_{\mathrm{cr}}$, the energy release rate is, for the first time, equal to the crack resistance:

$m_{i}=M_{\mathrm{cr}} \Rightarrow G_{i}=R(0) ;$ therefore $G_{\mathrm{cr}}=\frac{M_{\mathrm{cr}}^{2} F_{11}^{0}}{2}$

First cracking moment can be computed by using classic theory of reinforced concrete. It is well known that the parameter $M_{\mathrm{cr}}$ depends on the values of the axial force $n$ on the hinge. Therefore, $G_{\mathrm{cr}}$ is also a function of the axial force.

For higher values of the moment, damage evolution starts; Griffith criterion defines then a relationship between these two variables:

$\frac{m_{i}^{2} F_{11}^{0}}{2}=\left(1-d_{i}\right)^{2} G_{\mathrm{cr}}-q\left(1-d_{i}\right) \ln \left(1-d_{i}\right)$

According to (11), the moment is equal to $M_{\mathrm{cr}}$ for $d_{i}$ equal to 0 ; then increases for higher values of damage; reaches a maximum denoted $M_{\mathrm{u}}$, for $d_{i}$ equal to $d_{\mathrm{u}}$ and finally is equal to zero for $d_{i}$ equal to one. The value of the ultimate moment $M_{\mathrm{u}}$ of the cross section can also be determined by the conventional reinforced concrete theory and is again a function of the axial force on the hinge. The search of critical values of $m_{i}^{2}$ leads to the following equation:

$-2\left(1-d_{\mathrm{u}}\right) G_{\mathrm{cr}}+q\left[\ln \left(1-d_{\mathrm{u}}\right)+1\right]=0$

which allows for the computation of $d_{\mathrm{u}}$. Thus, the parameter $q$ can be obtained by the resolution of the following equation:

$\frac{M_{\mathrm{u}}^{2} F_{11}^{0}}{2}=\left(1-d_{\mathrm{u}}\right)^{2} G_{\mathrm{cr}}-q\left(1-d_{\mathrm{u}}\right) \ln \left(1-d_{\mathrm{u}}\right)$

The last member-dependent coefficients are those of the yield function: $k_{y}, c$. When the moment on the hinge reaches the value of the yield moment $M_{\mathrm{p}}$, the corresponding damage value $d_{\mathrm{p}}$ can also be computed by the Griffith criterion:

$\frac{M_{\mathrm{p}}^{2} F_{11}^{0}}{2\left(1-d_{\mathrm{p}}\right)}-G_{\mathrm{cr}}-q \frac{\ln \left(1-d_{\mathrm{p}}\right)}{1-d_{\mathrm{p}}}=0$

Additionally, for this value the yield function is for the first time equal to zero and the plastic rotation is still nil, therefore:

$M_{\mathrm{p}}-\left(1-d_{\mathrm{p}}\right) k_{y}=0$

Expression (15) allows for the determination of the coefficient $k_{y}$. The yield moment is again a function of the axial force and can be computed by the classic theory of reinforced concrete. 
Finally, the value of the plastic rotation $\Phi_{\mathrm{u}}^{\mathrm{p}}$ that corresponds to the ultimate moment $M_{\mathrm{u}}$ can be used to the computation of the last parameter of the model c. i.e. the expression $f=0$ leads to:

$M_{\mathrm{u}}-\left(1-d_{\mathrm{u}}\right)\left(c \Phi_{\mathrm{u}}^{\mathrm{p}}+k_{y}\right)=0$

It is assumed that interaction diagrams of $M_{\mathrm{cr}}, M_{\mathrm{p}}, M_{\mathrm{u}}$ and $\Phi_{\mathrm{u}}^{\mathrm{p}}$ can be computed with reasonable precision for cross sections of any shape and reinforcement. Specifically it is assumed that the ultimate plastic rotation can be estimated as:

$\Phi_{\mathrm{u}}^{\mathrm{p}} \cong \chi_{\mathrm{p}}^{\mathrm{u}} l_{\mathrm{p}}$

where $\chi_{\mathrm{p}}^{\mathrm{u}}$ is the ultimate plastic curvature and $l_{\mathrm{p}}$ an equivalent plastic hinge length.

\subsection{Other lumped damage mechanics concepts}

Further extensions of the model described in the precedent sections are possible and were implemented in the portal. The most important of them is the concept of unilateral damage. In frame members subjected to loadings that change sign, two different set of cracks appears in the frame member, one due to positive moments (positive cracks) and another as a consequence of negative moments (negative cracks). Within the framework of the lumped damage mechanics, this effect can be represented by using two sets of damage variables instead of one: $\mathbf{D}^{+}=\left(d_{i}^{+}, d_{j}^{+}\right)$ and $\mathbf{D}^{-}=\left(d_{i}^{-}, d_{j}^{-}\right)$, where the superscript indicates damage due to positive or negative moments (see Fig. 4). A frame element under this condition presents a behavior that can be described as 'unilateral'. This adjective, which comes from continuum damage mechanics, indicates that for positive moments, the negative cracks tend to close and have little influence on the member behavior and vice versa. A perfect unilateral behavior can be described by the following modification of the elasticity law (3):

$\varepsilon-\varepsilon_{\mathbf{p}}=\mathbf{F}\left(\mathbf{D}^{+}\right)\langle\boldsymbol{\sigma}\rangle_{+}+\mathbf{F}\left(\mathbf{D}^{-}\right)\langle\boldsymbol{\sigma}\rangle_{-}$

where the symbols $\langle x\rangle_{+}$and $\langle x\rangle_{-}$indicate, respectively, the positive and negative part of the variable $x$. i.e. $\langle x\rangle_{+}=x$ if $x>0 ;\langle x\rangle_{+}=0$ otherwise. $\langle x\rangle_{-}=x$ if $x<0 ;\langle x\rangle_{-}=0$ otherwise. It can be noticed that positive damage has no influence at all in the compliance of the structure if the moments are negative and vice versa.

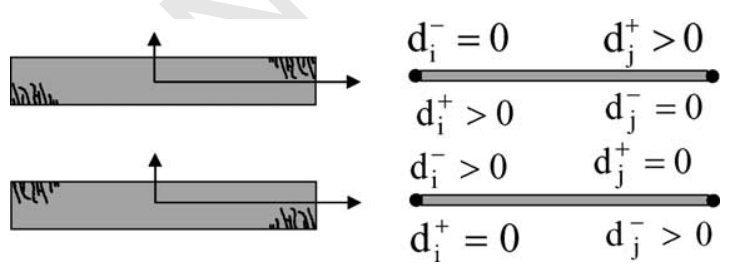

Fig. 4. Unilateral damage.
Two different energy release rates per hinge are now defined: $G_{i}^{+}$and $G_{i}^{-}$. They are given by an expression similar to (5) except that the moment is substituted by its positive or the negative part and the damage for the corresponding positive or negative variable. The yield function can also be modified by the definition of an effective moment with the positive damage variable if positive cracks are open and vice versa (see [2], for additional details).

Another extension of the model consists in the use of modified forms of the Griffith criterion. In particular the one described in [9], was included in the portal in order to represent low cycle fatigue effects.

Finally, although models for steel structures $[5,6]$ and three-dimensional reinforced concrete frames [4] have been developed and tested, they have not been implemented in the portal yet.

\subsection{A finite element based on lumped damage mechanics}

A finite element can be described as a set of equations that relates the element degrees of freedom $\mathbf{u}^{\mathbf{t}}=\left(u_{i}, v_{i}, \theta_{i}, u_{j}\right.$, $v_{j}, \theta_{j}$ ) with the nodal forces $\mathbf{Q}$ (see Fig. 5). The member strain matrix and the degrees of freedom of the element are related by the following kinematic equations:

$\dot{\phi}_{i}=\frac{\sin \alpha_{i j}}{L_{i j}} \dot{u}_{i}-\frac{\cos \alpha_{i j}}{L_{i j}} \dot{v}_{i}+\dot{\theta}_{j}-\frac{\sin \alpha_{i j}}{L_{i j}} \dot{u}_{j}+\frac{\cos \alpha_{i j}}{L_{i j}} \dot{v}_{j}$

$\dot{\phi}_{j}=\frac{\sin \alpha_{i j}}{L_{i j}} \dot{u}_{i}-\frac{\cos \alpha_{i j}}{L_{i j}} \dot{v}_{i}-\frac{\sin \alpha_{i j}}{L_{i j}} \dot{u}_{j}+\frac{\cos \alpha_{i j}}{L_{i j}} \dot{v}_{j}+\dot{\theta}_{j} ;$

$\dot{\delta}=-\dot{u}_{i} \cos \alpha_{i j}-\dot{v}_{i} \sin \alpha_{i j}+\dot{u}_{j} \cos \alpha_{i j}-\dot{v}_{j} \sin \alpha_{i j}$

i.e. $\dot{\boldsymbol{\varepsilon}}=\mathbf{B} \dot{\mathbf{u}}$

where $\mathbf{B}$ is the transformation matrix. If geometrically nonlinear effects are taken into account, the angle $\alpha_{i j}$ and the length $L_{i j}$ are not constant but depend on the displacements u. Geometrically nonlinear effects are included in the portal in this way.

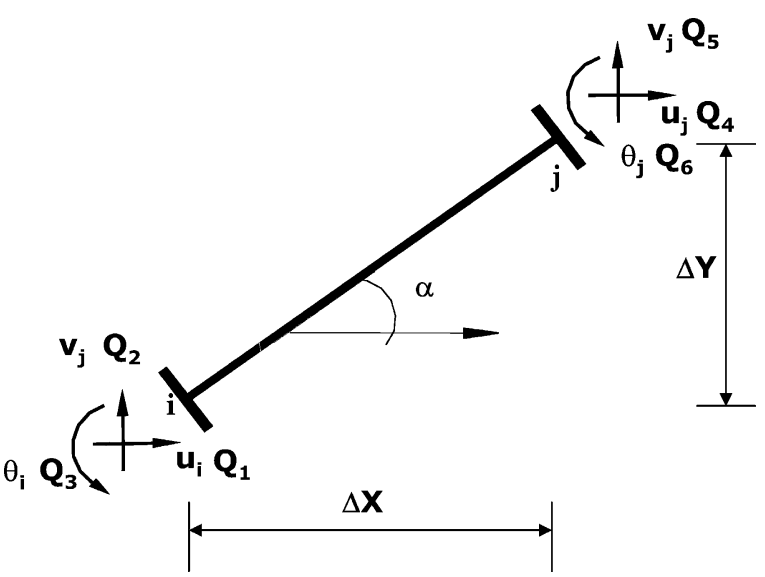

Fig. 5. Degrees of freedom of a frame element and nodal forces. 


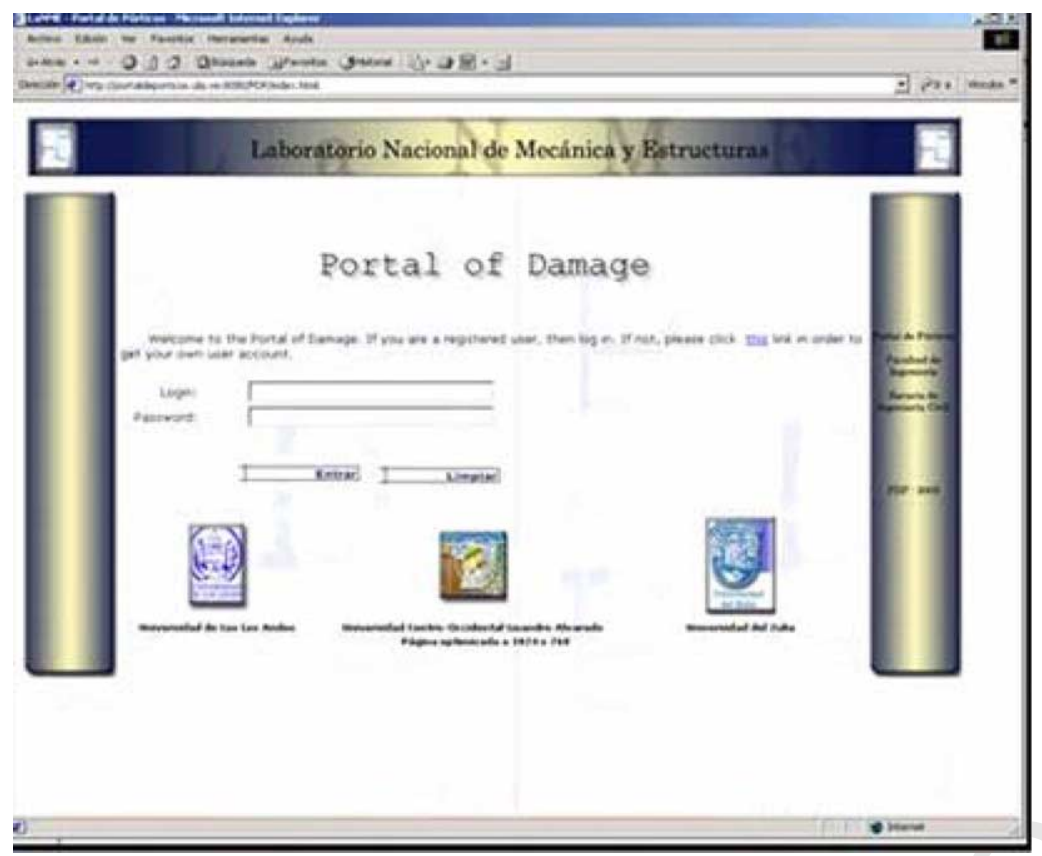

Fig. 6. Main page of the portal of damage.

The nodal forces and the stress matrix are also related by the following expression:

$\mathbf{Q}=\mathbf{B}^{\mathrm{t}} \boldsymbol{\sigma}$

The set of equations composed by $(19,20)$ and the constitutive law described in the previous sections define a finite element that can be included in the library of elements of commercial nonlinear analysis programs [3]. Additionally, a new finite element program that can be accessed via web has also been developed and is described in Section 3.

\section{Description of the portal}

\subsection{Links of the portal}

The portal can be accessed in the address http:// portalofdamage.ula.ve. The system has a user's data base, thus she/he has to register in her/his first visit. After registration, the user has access to the five links of the system: pre-processor, processor, post-processor, user manual and theory manual (see Fig. 6).

Within the pre-processor (a Java program), the user has different menus for the description of the frame geometry, the boundary conditions, the dimensions of the elements'

\section{Pre-Processor}

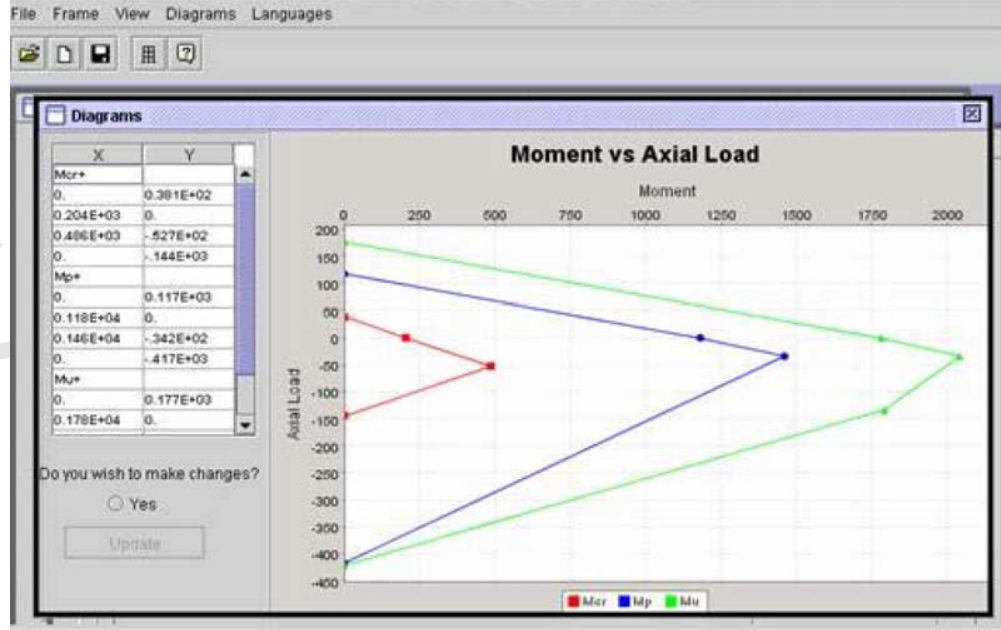

Fig. 7. Diagrams of interaction computed by the pre-processor 


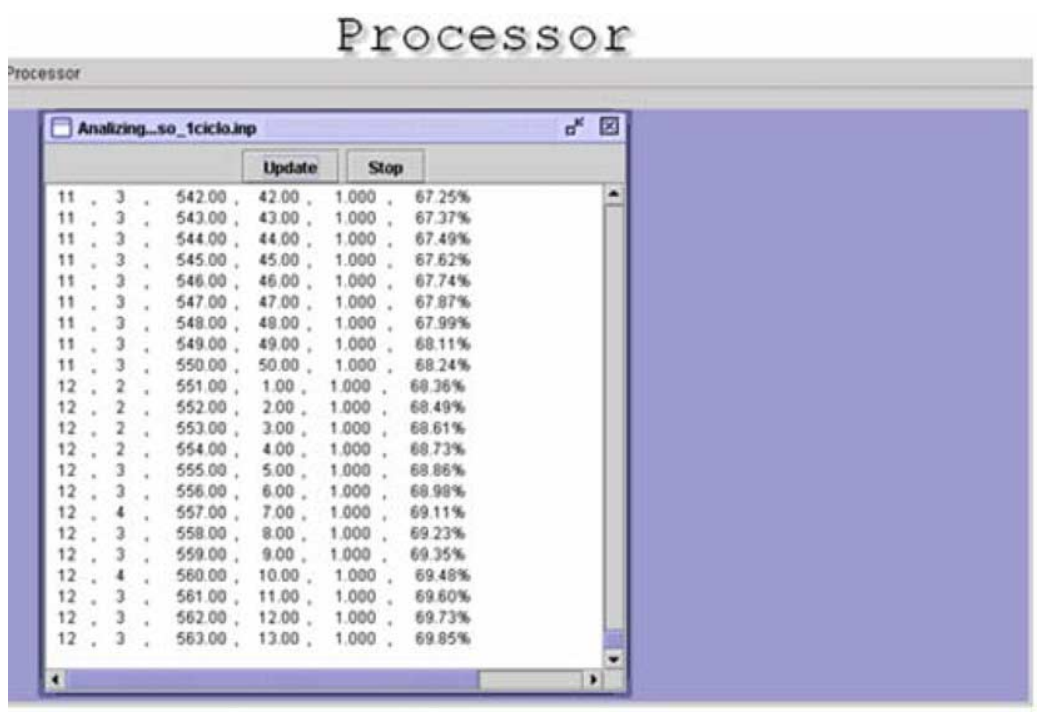

Fig. 8. Monitoring of an analysis in the portal.

cross sections (only rectangular cross sections are included so far), the amount and location of the longitudinal and transversal reinforcement, the uniaxial behavior of the concrete and the reinforcement and, finally, the loading. The user can impose distributed forces on the elements, and displacements, accelerations or forces on the nodes.

However, as indicated in Section 3, the model needs interaction diagrams of the first cracking moment, yielding moment, ultimate moment and curvature. All these diagrams are computed by a FORTRAN program embedded into the pre-processor called diagram generator. The diagram generator uses as input the uniaxial behavior of the materials, the dimensions of the cross section and the amount of the reinforcement. This process is carried out by using standard methods of the classic reinforced concrete theory for confined (Kent and Park model) or non-confined elements (Hognestad model). The details of these procedures can be seen in any textbook on reinforced concrete, for instance [10]. The user instructs the portal to perform the generation of the interaction diagrams in one of the menus of the preprocessor. The results of these computations are shown, graphically, by the portal (see Fig. 7). Notice that a table with the coordinates of the diagrams is also created. The user can modify these values. This is useful for some special applications. Errors up to $15 \%$ in the computed diagrams can be expected by using standard reinforced concrete theory. In the case of very important structures, it can be convenient the execution of experimental tests on some typical elements of the frame. The experimental results can be inserted directly in the analysis by the modification of the diagram tables. Numerical results for single elements of other programs or procedures can also be used in this same way.

\section{Post-Processor}

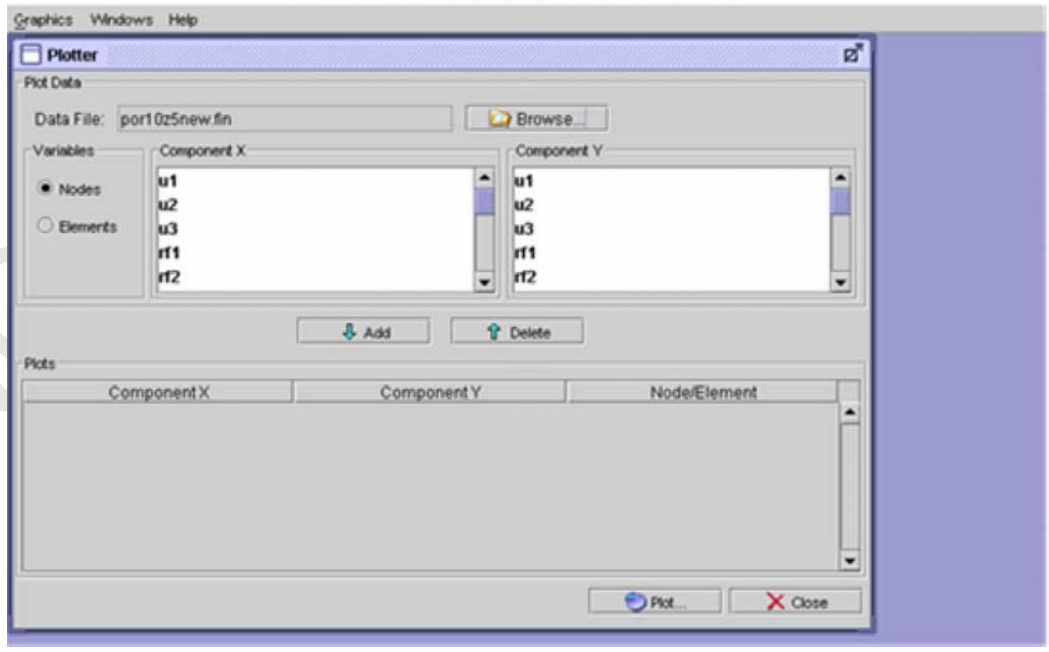

Fig. 9. Graphic post-processor. 


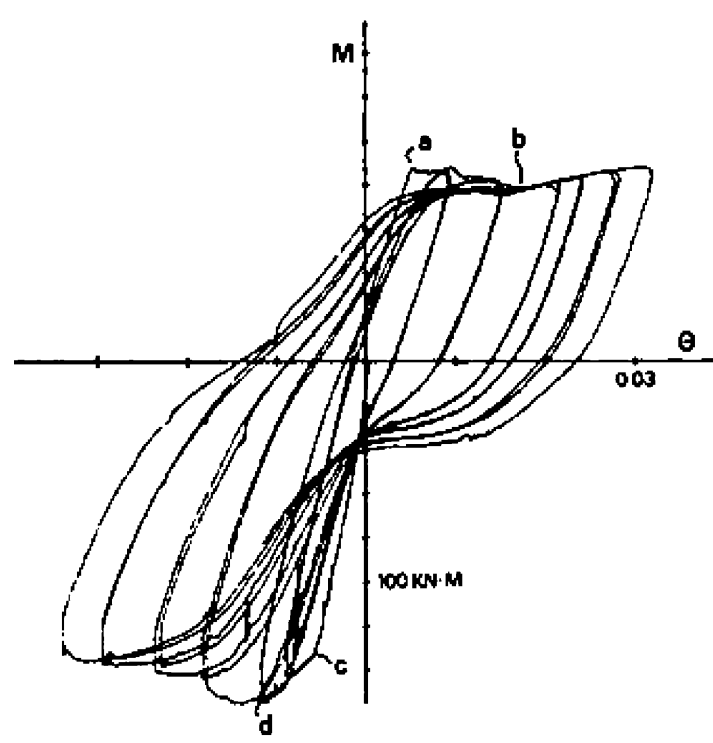

(a)

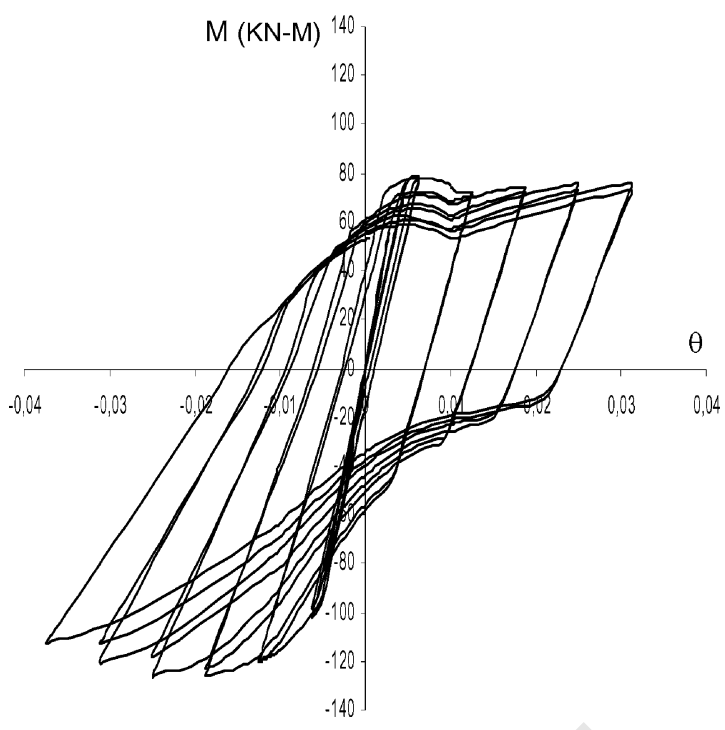

(b)

Fig. 10. (a) Moment vs. rotation in a cantilever specimen after [12] (b) numerical simulation.

Two different kinds of data files are generated by the preprocessor. The first one has the raw data of the frame including the uniaxial behavior of the materials and details of the cross section. A second data file is also generated; it has the values of the interaction diagrams of the model parameters instead of the element details. Only the second kind of data files can be processed by the FE program.

The second link of the portal gives access to a page called processor. In this page, the user may select a data file in her/his account and process it with the FE program. The user may also abort the analysis or monitor the process by opening or updating a file with the relevant information (see Fig. 8).

When the process is successfully finished, the user may download a results file in text format or may proceed to a graphic evaluation of these results with the third main link of the portal: the post-processor.

With the post-processor (see Fig. 9), the user may plot histories of element variables (damage, generalized stresses or strains, plastic rotations) or node variables (forces, displacements, velocities, accelerations) and variable vs. variable graphs. Damage distribution over the frame at any instant of the loading can also be plotted.

\subsection{The finite element program}

All the previously described elements of the portal (preprocessor, processor and post-processor) are Java programs.
In particular, the processor is a Java interface with a Fortran FE program. This program manages the step by step procedure and solves the dynamic equilibrium Eq. (21) at a given instant after time discretization by using the Newmark method:

$\mathbf{L}(\mathbf{U})=\sum_{b=1}^{m} \mathbf{Q}(\mathbf{U})_{b}+\mathbf{I}(\mathbf{U})-\mathbf{P}=0$

where $\mathbf{I}$ represents the inertia forces, $\mathbf{U}$ is the matrix of nodal displacements of the entire frame, $\mathbf{P}$ is the external forces and $m$ represents the number of frame members. The nonlinear problem (21) is solved by a standard Newton method. For each iteration of the global problem (21), $m$ local problems have to be solved. Each local problem consists on the computation of the nodal forces $\mathbf{Q}$ from the nodal displacements $\mathbf{U}$ by using the constitutive law and kinematic equations described in Section 2. The local problem is also nonlinear and is solved by the Newton method too. In fact, the local problem can become highly nonlinear for high values of damage (over 0.5 ). However, in a frame only few elements reach such high values of damage. As a result, the convergence requirements of the $m$ local and the global problems are very diverse. Thus, a substepping strategy has been adopted: the local problem in those elements, where damage is concentrated is solved by

Table 1

Data for the simulation presented in Fig. 10

\begin{tabular}{|c|c|c|c|c|c|c|c|c|c|c|}
\hline$F^{\prime} c\left(\mathrm{~kg} / \mathrm{cm}^{2}\right)$ & $e_{0}$ & $e_{\mathrm{uc}}$ & $E\left(\mathrm{~kg} / \mathrm{cm}^{2}\right)$ & $e_{\mathrm{ccu}}$ & $e_{\mathrm{sm}}$ & $e_{\mathrm{y}}$ & $\mathrm{e}_{\mathrm{sh}}$ & $f_{\mathrm{su}}\left(\mathrm{kg} / \mathrm{cm}^{2}\right)$ & $f_{\mathrm{y}}\left(\mathrm{kg} / \mathrm{cm}^{2}\right)$ & $f_{\mathrm{yh}}\left(\mathrm{kg} / \mathrm{cm}^{2}\right)$ \\
\hline 468.05 & 0.002 & 0.004 & 200.000 & 0.005 & 0.125 & 0.002 & 0.006 & 6038.7 & 4313.4 & 4313.4 \\
\hline
\end{tabular}

Note: $\mathrm{kg} / \mathrm{cm}^{2}=0.0980665 \mathrm{MPa}$. 

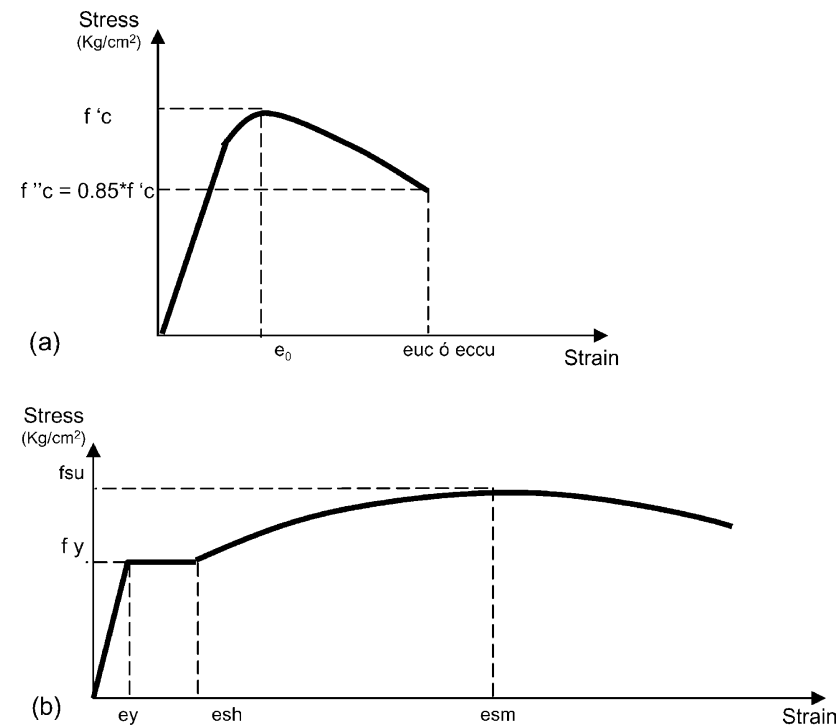

Fig. 11. Data for the description of the uniaxial behavior. (a) Concrete (b) reinforcement.

the discretization of the global time step in smaller local steps (see [4]).

It can be noticed that lumped damage laws are multicriteria models. Therefore special kinds of elastic predictor-inelastic corrector algorithms are needed. In particular, the one studied in [11] was used in the program.

\section{Numerical examples}

Some numerical simulations carried out with the portal are shown in this section. The goal of the two first examples is to show the precision that can be expected by using the portal. These examples correspond to the numerical simulation of tests reported in the literature. The last case is designed to show what could be a real application of the portal: the numerical simulation of a building designed after the current Venezuelan code.

The first example is a RC column in cantilever subjected in laboratory to a complex loading program that represents the actions that a building column must withstand during an earthquake. They include cyclic lateral displacements and variable axial forces [12]. The experimental behavior is represented in the graph of lateral displacements vs. lateral forces shown in Fig. 10a. The numerical simulation obtained with the portal is shown in Fig. 10b. The data used for the simulation is shown in Table 1. The meaning of the symbols used in Table 1 is shown in Fig. 11.

It can be noticed, that although the results are very good qualitatively, the portal underestimates the strength of the column. This is a consequence of using classic reinforced concrete theory.

A test like this one could also be part of the assessment process of an entire structure. For instance, the specimen could be a replica of one column of the structure that must be evaluated. The diagrams generated by the portal can be modified to fit the experimental results in order to carry out a more precise simulation of the structure as mentioned in Section 3. The numerical simulation of the same test carried out with modified diagrams is shown in Fig. 12b. The original and modified diagrams, i.e. the ones used in, respectively, the simulations shown in Figs. 10b and 12b are indicated in Fig. 13.

The second example is a two-story $\mathrm{RC}$ frame that was subjected in laboratory to constant axial forces and to imposed lateral displacement at the top of the frame as shown in Fig. 14 (see [13]). The experimental results are shown in Fig. 15a in a graph of lateral displacement vs. lateral force. The results of the numerical simulation

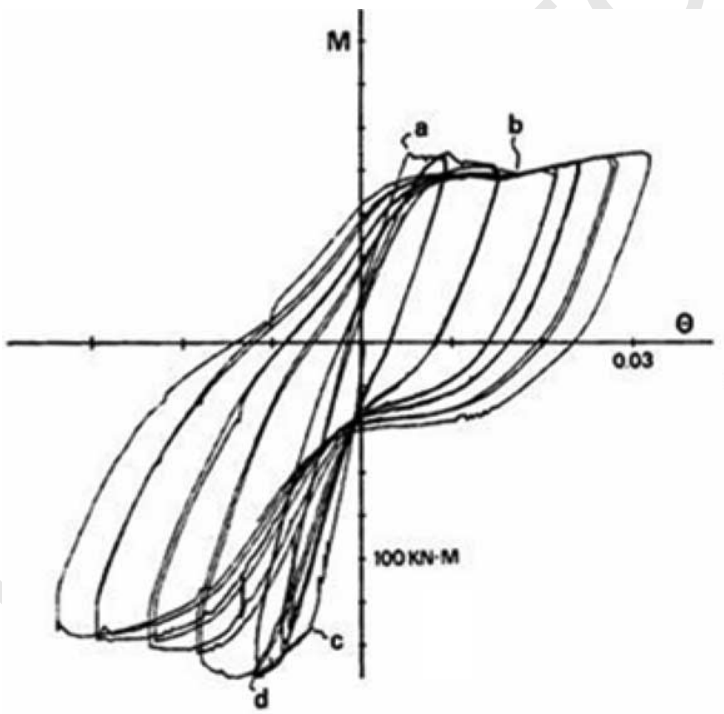

(a)

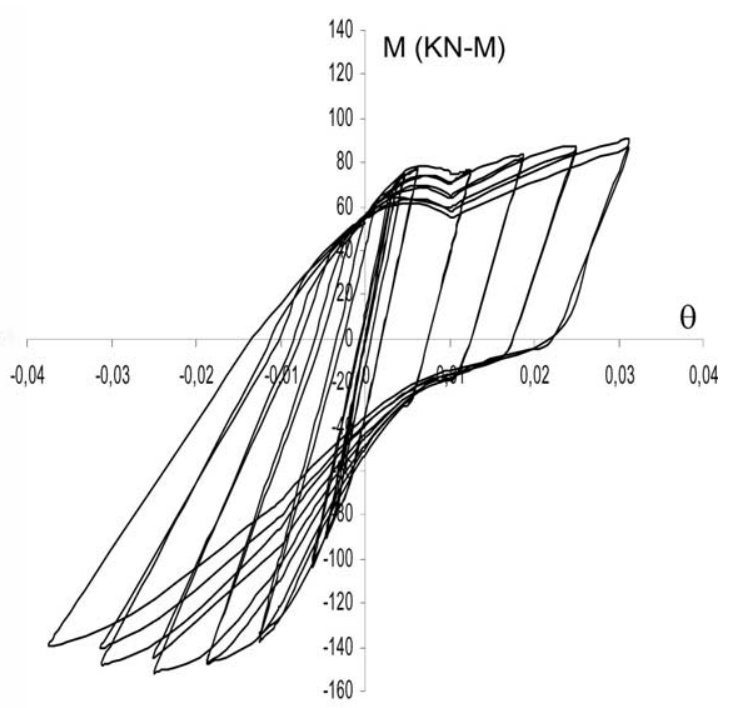

(b)

Fig. 12. (a) Moment vs. rotation in a cantilever specimen after [12] (b) numerical simulation. 

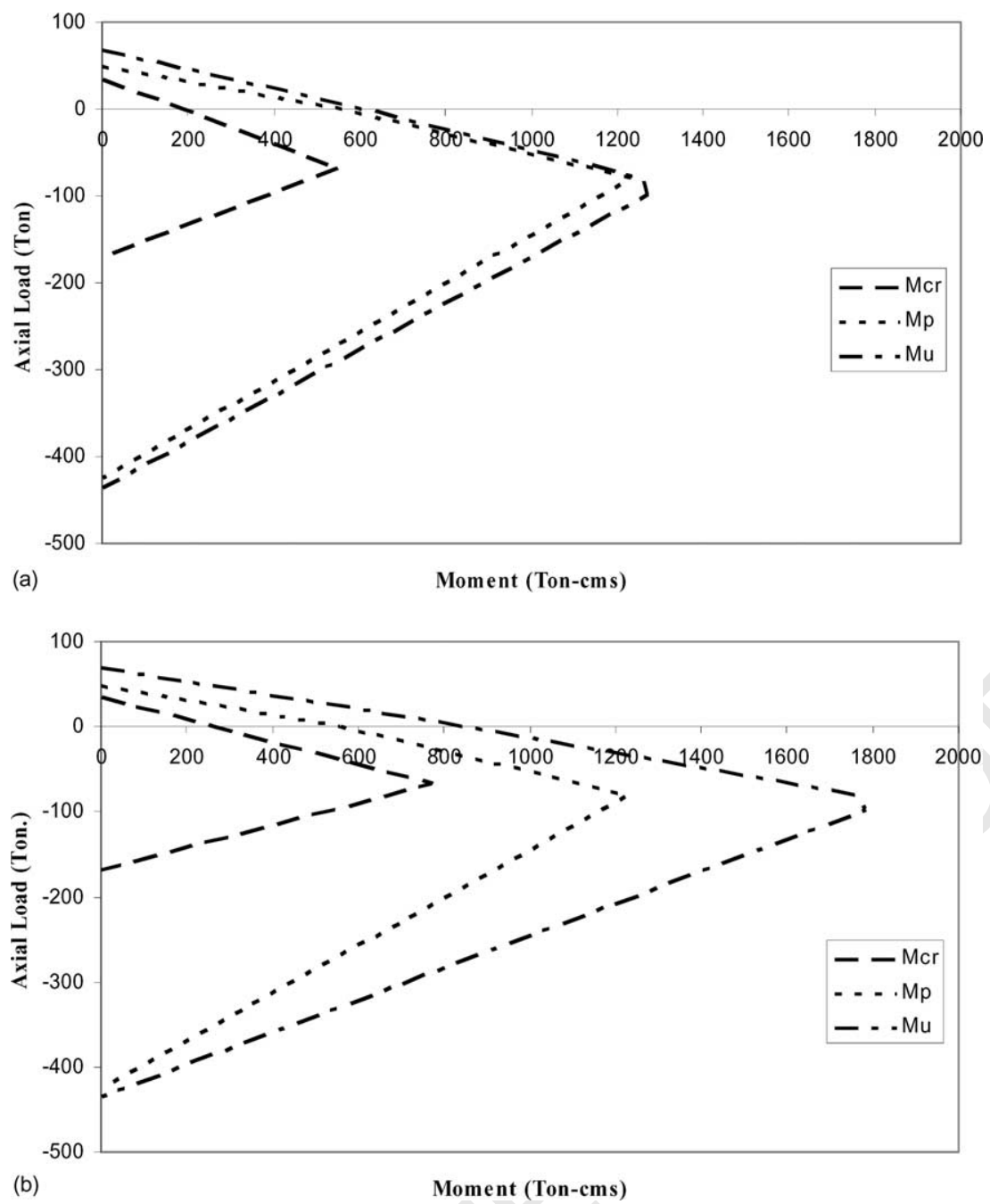

Fig. 13. (a) Interaction diagrams used in the simulation of Fig. 10b. (b) Interaction diagrams used in the simulation of Fig. 12b.
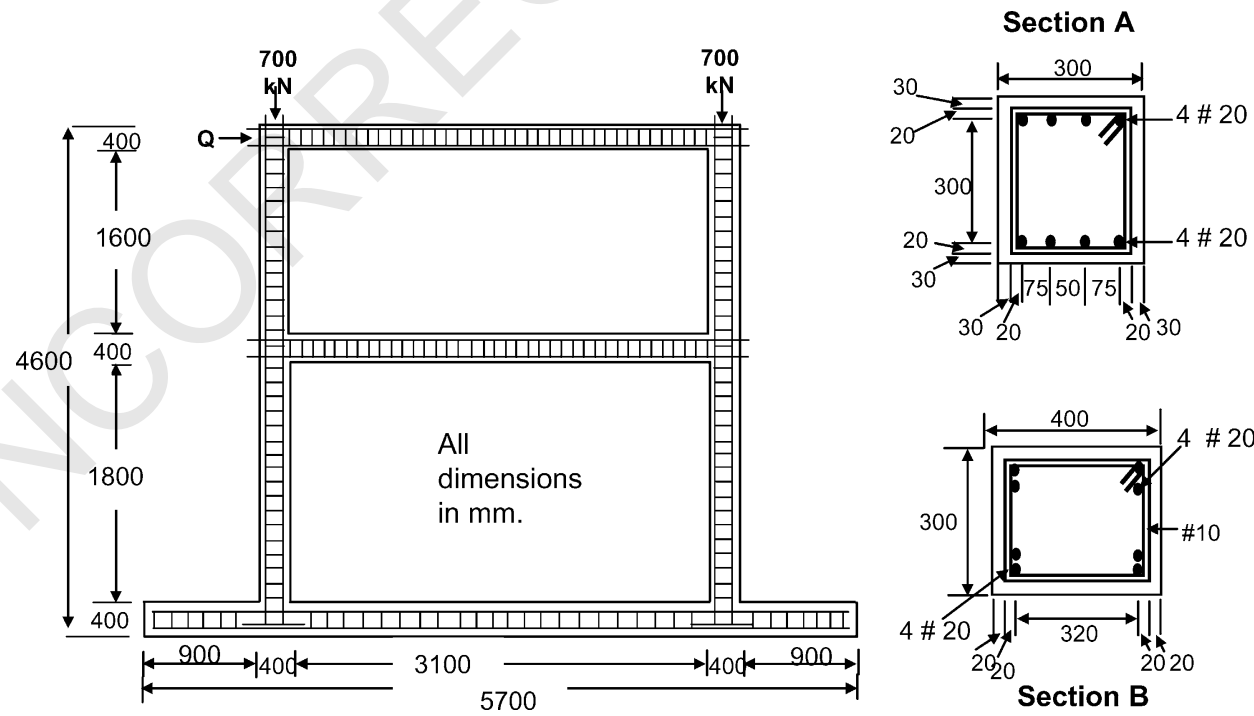

Fig. 14. Push over test on a RC frame after [13]. 


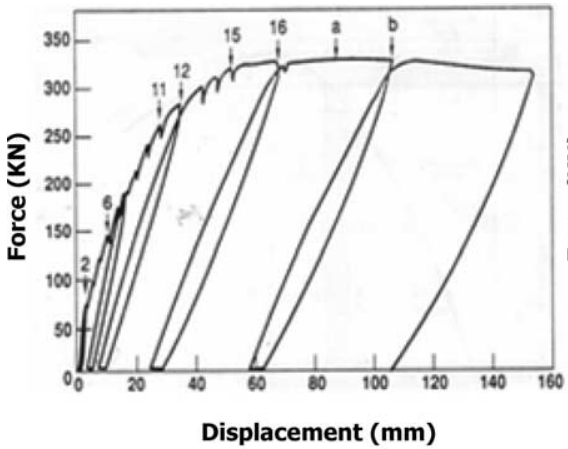

(a)

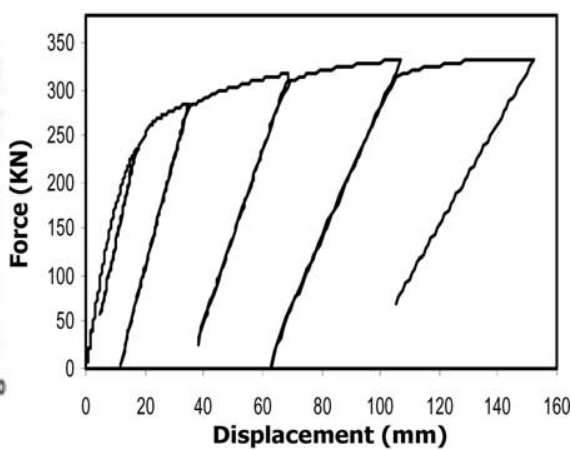

(b)

Fig. 15. (a) Force vs. displacement in a frame after [13] (b) numerical simulation.

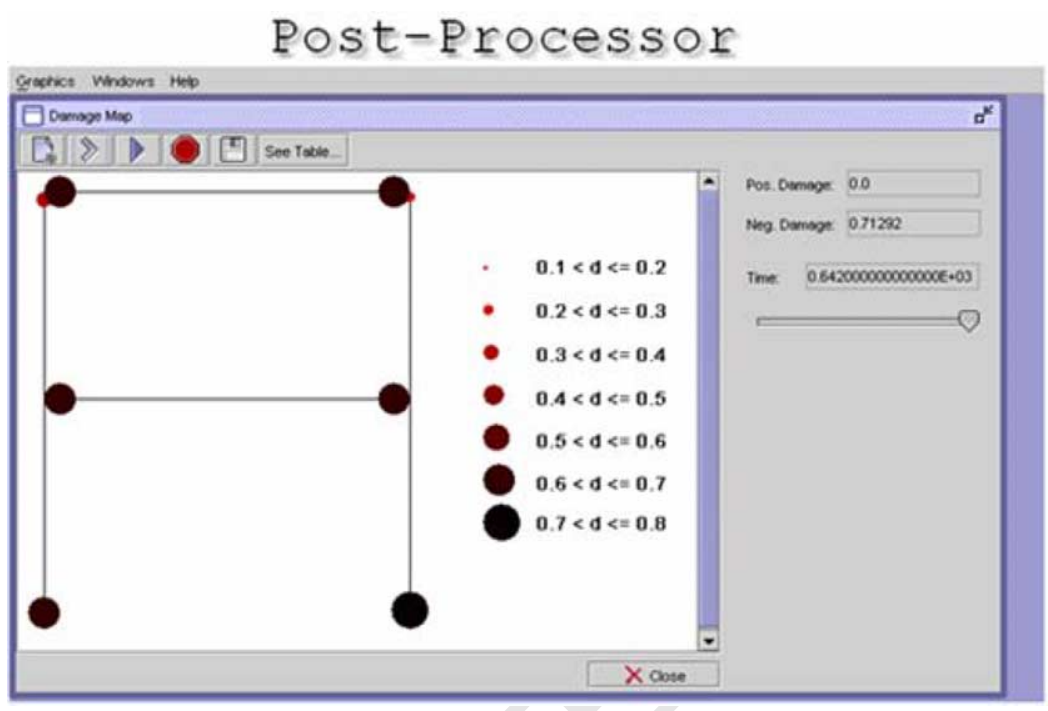

Fig. 16. Damage distribution at the end of the test.

with the portal are shown in Figs. 15b and 16. Fig. 16 shows the damage distribution at the end of the simulation. The simulation was carried out using the diagrams of the portal without modifications. The data used for the generation of the diagrams is given in Table 2 .

This damage distribution can be used to establish the vulnerability of the structure as well as the feasibility of reparation as discussed in [14]. For instance, values of damage less than 0.2 can be described as minor, repairable damages are in the range $[0.2,0.45]$ and values over 0.6 corresponds to progressive collapse. Theoretical and experimental justification for these values can be found in [14].

The last example shows a simulation of what could be a real application of the portal. A 10-story frame [15] (see Fig. 17) designed according to the current Venezuelan code, which is strongly inspired on the USA one, was subjected to two different acceleration records. The first one was artificially generated from the spectrum of the design earthquake that corresponds to medium seismic risk in Venezuela. The damage distribution at the end of the simulation is shown in Fig. 18. The maximum damage observed is 0.37 , which corresponds to repairable damage, and a scattered pattern of damage in beams and columns can be observed. These results indicate an adequate design of the frame for this loading. The second one was also artificially generated, but this time from the spectrum of a design earthquake for the most unfavorable region considered in the Venezuelan code. The intention of this

Table 2

Data for the simulation presented in Figs. $15 \mathrm{~b}$ and 16

\begin{tabular}{lllllllllll}
\hline$F^{\prime} c\left(\mathrm{~kg} / \mathrm{cm}^{2}\right)$ & $e_{0}$ & $e_{\mathrm{uc}}$ & $E\left(\mathrm{~kg} / \mathrm{cm}^{2}\right)$ & $e_{\mathrm{ccu}}$ & $e_{\mathrm{sm}}$ & $e_{\mathrm{y}}$ & $\mathrm{e}_{\mathrm{sh}}$ & $f_{\mathrm{su}}\left(\mathrm{kg} / \mathrm{cm}^{2}\right)$ & $f_{\mathrm{y}}\left(\mathrm{kg} / \mathrm{cm}^{2}\right)$ & $f_{\mathrm{yh}}\left(\mathrm{kg} / \mathrm{cm}^{2}\right)$ \\
\hline 480.00 & 0.0018 & 0.004 & 200.000 & 0.0054 & 0.11 & 0.0022 & 0.0095 & 6077.41 & 4262.43 & 4629.53 \\
\hline
\end{tabular}

Note: $\mathrm{kg} / \mathrm{cm}^{2}=0.0980665 \mathrm{MPa}$. 


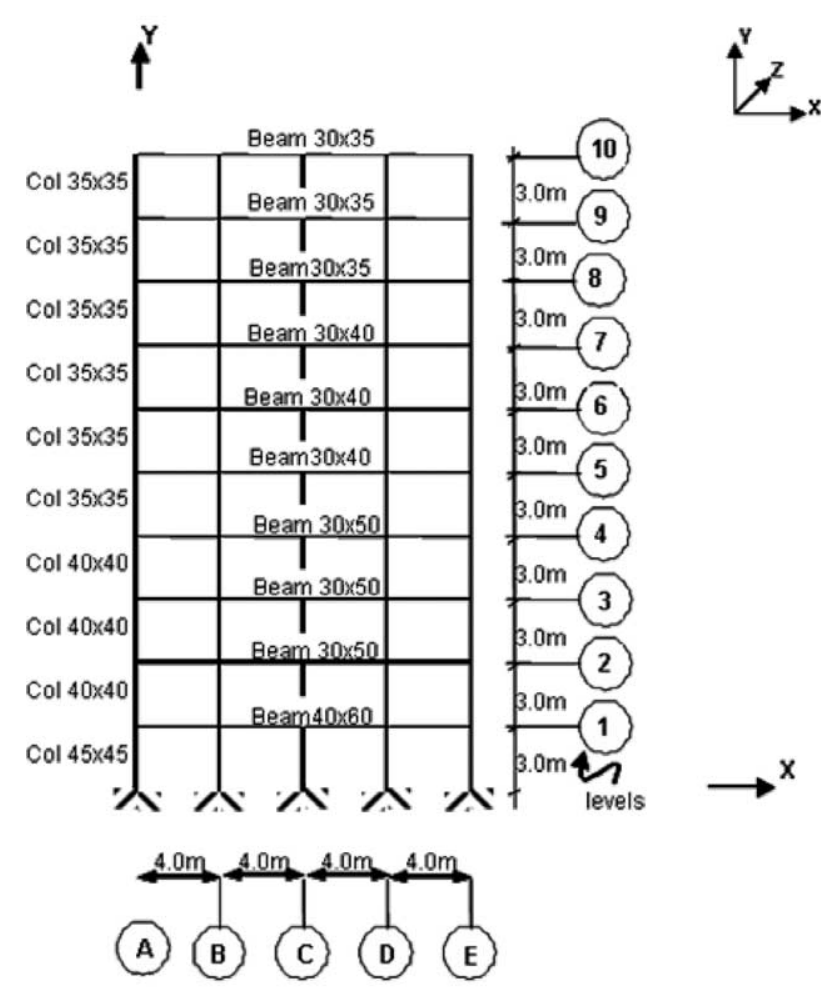

Fig. 17. Ten-story RC frame [15].

example is to evaluate the behavior of an under-designed building. The damage distribution at the end of the second simulation is shown in Fig. 19. The maximum damage is this time 0.69 and other high values can be observed in the middle zone of the frame. Such high values of damage indicate that the frame was on the verge of structural collapse. As a conclusion, a building like this one built in a zone, where such an overload is likely to occur deserves special attention.

\section{Final remarks}

This paper describes a web-based nonlinear, dynamic finite element program. The authors do not have other references to compare with in the field of structural and solid mechanics. Beside the arguments mentioned in the introduction of this paper, web-based FE programs also exhibit obvious advantages from the point of view of the author's rights protection.

It must be underlined that the system is just a prototype and that the debugging capacity of the team that developed the portal is limited. The portal has been tested on a restricted number of examples, but there may be some bugs hidden in the software. The FE program is not yet very efficient and computational times can be significantly reduced. An effort of optimization and parallelization of the FE program has already been initiated. There are convergence problems in the case of severe overloads that lead to very high values of damage. There may be several reasons for these problems:

(a) Unknown bugs in FE program

(b) Possible failures of the chosen Newton method to reach convergence

(c) Non-existence of mathematical solutions

It is important to clarify the last potential lack of convergence cause. Any realistic model of the process of damage and collapse of structures under mechanical overloads must include that possibility. In fact, structural collapse can be mathematically defined in that way. However, so far there is no criterion that establishes in the most general case the existence of mathematical solutions to the lumped damage problem. Some efforts have been undertaken in that direction [16] but this is still an open problem. The goal would be the development of uniqueness and existence

\section{Post-Processor}

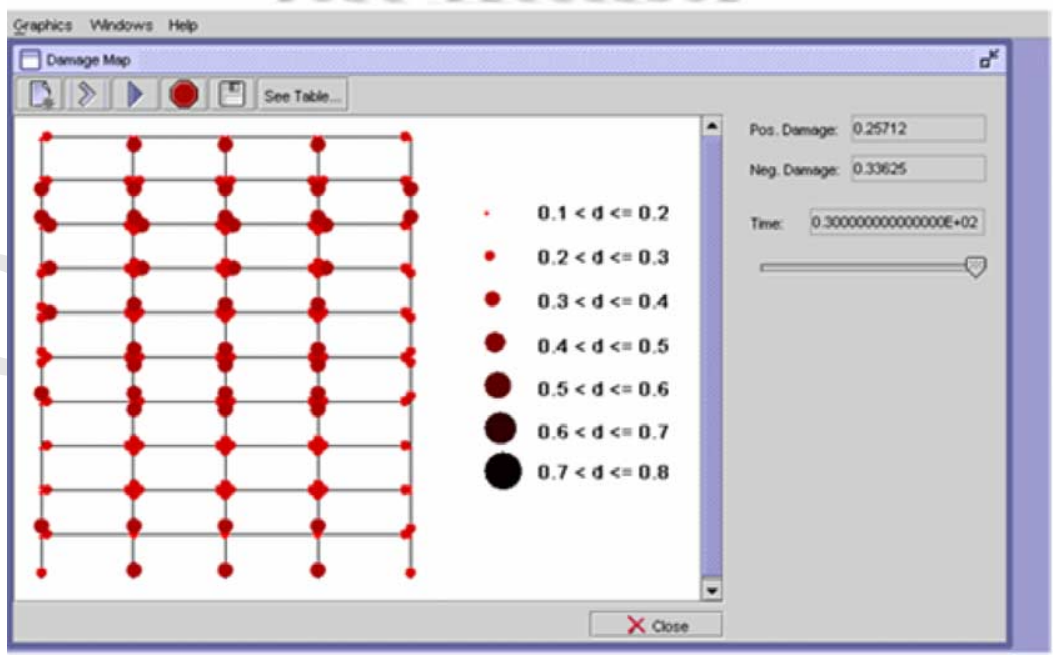

Fig. 18. Damage distribution at the end of the analysis with the design earthquake. 


\section{Post-Processor}

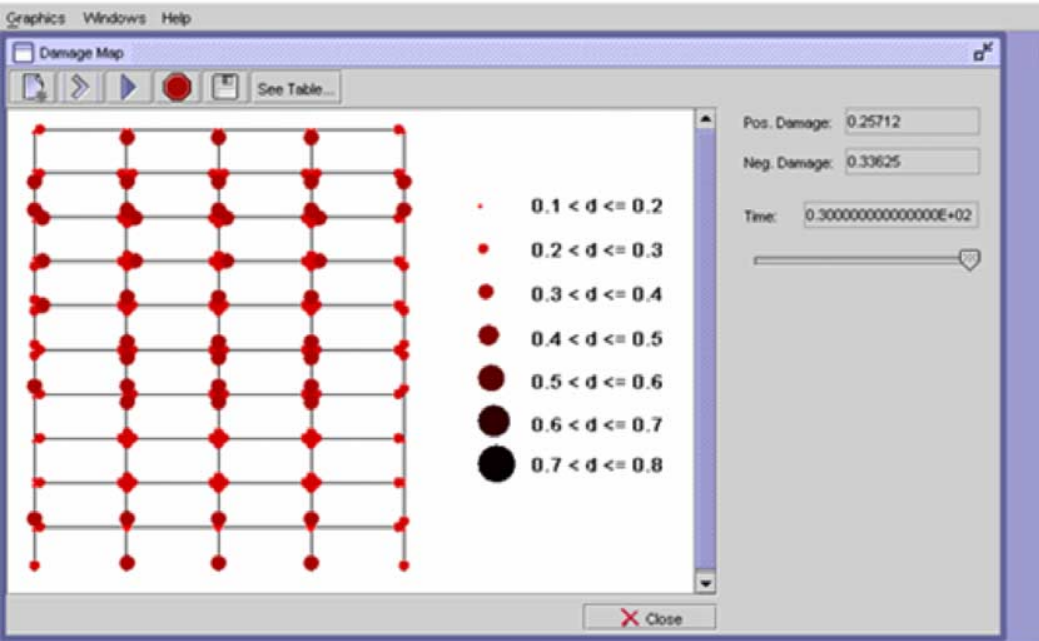

Fig. 19. Damage distribution at the end of the analysis with a stronger earthquake.

criteria that could be numerically evaluated by the portal and predict in this way the structural collapse of the frame. In the absence of such criterion, it is not possible to discard the first or second cause of non-convergence if the portal fails to finish a particular application.

The use of the portal is free and will remain free for academic purposes within the limits of the resources allocated to it.

\section{Acknowledgements}

The results presented in this paper were obtained in the course of an investigation sponsored by FONACIT.

\section{References}

[1] Cipollina A, López-Inojosa A, Flórez-López J. A simplified damage mechanics approach to nonlinear analysis of frames. Comput Struct 1995;54(6):1113-26.

[2] Flórez-López J. Frame analysis and continuum damage mechanics. J Eur Mech 1998;17(2):269-84.

[3] Perdomo ME, Ramirez A, Flórez-López J. Simulation of damage in RC frames with variable axial forces. Earthquake Eng Struct Dyn 1999;28(3):311-28.

[4] Marante ME, Flórez-López J. Three-dimensional analysis of reinforced concrete frames based on lumped damage mechanics. Int J Solids Struct 2003;40(19):5109-23.
[5] Inglessis P, Medina S, Lopez A, Febres R, Flórez-López J. Modeling of local buckling in tubular steel frames by using plastic hinges with damage. Steel Compos Struct 2002;2(1):21-34.

[6] Febres R, Inglessis P, Florez-Lopez J. Modeling of local buckling in tubular steel frames subjected to cyclic loading. Comput Struct 2003; 81:2237-47.

[7] Griffith AA. The phenomenon of rupture and flow in solids. Phil Trans R Soc Lond 1921;A221:163-97.

[8] Broek D. Elementary engineering fracture mechanics. Dordrecht: Martinus Nijhoff Publishers; 1986.

[9] Thomson E, Bendito A, Flórez-López J. Simplified model of low cycle fatigue for RC frames. J Struct Eng ASCE 1998;124(9): 1082-6.

[10] Park R, Paulay T. Reinforced concrete structures. New York: Wiley; 1975.

[11] Simo J, Kennedy A, Govindjee S. Non-smooth multisurface plasticity and viscoelasticity, Loading/unloading conditions and numerical algorithms. Int J Numer Methods Eng 1988;26: 2161-85.

[12] Abrams DP. Influence of axial force variations on flexural behavior of reinforced concrete columns. ACI Struct J 1987; May-June.

[13] Vechio FJ, Emara MB. Shear deformation in reinforced concrete frames. ACI Struct J 1992;89(1)

[14] Alarcón E, Recuero A, Perera R, Lopez C, Gutierrez JP, De Diego A, et al. A reparability index for reinforced concrete members based on fracture mechanics. Eng Struct 2001;23(6):687-97.

[15] Pernia F, Estudio paramétrico del análisis de push over aplicado a edificios de concreto armado, Thesis, University of los Andes, Mérida (in progress).

[16] Marante ME, Picón R, Flórez-López J, Analysis of localization in frame members with plastic hinges, Int $\mathbf{J}$ Solids Struct in press. 